\title{
Enhanced quasi-static and dynamic shear properties by heterogeneous gradient and lamella structures in 301 stainless steels
}

\author{
Junxia Xing ${ }^{\mathrm{a}, \mathrm{b}}$, Fuping Yuan ${ }^{\mathrm{a}, \mathrm{b}, *}$, Xiaolei $\mathrm{Wu}^{\mathrm{a}, \mathrm{b}}$ \\ a State Key Laboratory of Nonlinear Mechanics, Institute of Mechanics, Chinese Academy of Sciences, No.15, North 4th Ring, West Road, Beijing 100190, \\ People's Republic of China \\ ${ }^{\mathrm{b}}$ School of Engineering Science, University of Chinese Academy of Sciences, Beijing 100190, People's Republic of China
}

\section{A R T I C L E I N F O}

\section{Keywords:}

Hopkinson-bar

Dynamic shear response

Adiabatic shear band

Gradient structure

Heterogeneous lamella structure

\begin{abstract}
A B S T R A C T
In the present study, quasi-static and dynamic shear response of 301 stainless steel (SS) with gradient structure (GS) and heterogeneous lamella structure (HLS) were investigated by uniaxial tensile tests and Hopkinson-bar tests with hat-shaped specimens. The 301 SS with GS and HLS show a good combination of strength and ductility under quasi-static tensile tests, which is due to the back stress hardening for heterogeneous structures. Before the formation of adiabatic shear band (ASB), the dynamic shear response of 301 SS with coarse-grained (CG) austenitic structure shows a strong linear hardening stage and a plateau stage, which are due to the martensite transformation and the continuous deformation through strain partitioning between different phases, respectively. For 301 SS with CG austenitic structure, the grain size was observed to significantly refined in the ASB, while the reverse phase transformation occurs and the austenite phase increases significantly again in the ASB with increasing shear displacement, resulting in a hardness valley in the ASB at the shear displacement of $2.0 \mathrm{~mm}$. The GS and HLS show excellent dynamic shear properties, this could be due to the back stress hardening for either macroscopically or microscopically heterogeneous structures. The HLS seems to have better impact shear properties than the GS, which indicates that the HLS with microscopically heterogeneous structures could delay the formation of ASB in a better way than the GS with macroscopically heterogeneous structures. The results in the current study could provide insights for obtaining better mechanical properties under dynamic conditions.
\end{abstract}

\section{Introduction}

Stainless steels have been considered as an important class of alloys for structural materials due to their excellent weldability, good formability, high corrosion resistance, high work hardening ability and high energy absorption capability [1-3]. When the metastable austenitic stainless steels (SS) are deformed at ambient temperature, they show increased strain hardening rate and uniform elongation due to the austenite-to-martensite transformation, which is so called transformation-induced plasticity (TRIP) [4]. However, the yield strength for the coarse-grained (CG) austenitic SS is relatively low which limits their applications for structural materials.

It has always been a challenge to obtain both high strength and high ductility in metals and alloys although it is desirable in structural applications [5-8]. High strength can be easily achieved by grain refinement into ultrafine-grained (UFG) or nano-grained (NG) structures, however this usually accompanies with sacrifice of ductility
$[9,10]$. A promising strategy has been considered for simultaneously achieving high strength and ductility by combining several strain hardening mechanisms together in steels [11-15]. For example, the strength and ductility have been reported to improve simultaneously in a TRIP-maraging steel due to combination of three effects, i.e. the TRIP effect, the maraging effect by nano-precipitation and the composite effect due to strain partitioning [11]. Similarly, heterogeneous UFG SS combining with TRIP effect and Lüders bands also exhibited both high strength and good ductility [16-19]. Recently, several strategies employing hierarchical structures, such as gradient structure (GS) and heterogeneous lamella structure (HLS) [6,20-23], have been reported to produce a superior synergy of yield strength and ductility. In these structures, high ductility can be attributed to the extra strain hardening due to the change of stress state and the presence of strain gradient, which generates geometrically necessary dislocations and back stress hardening [6]. In our recent research [23], high strength and ductility have been also achieved in a 304 SS by combining the

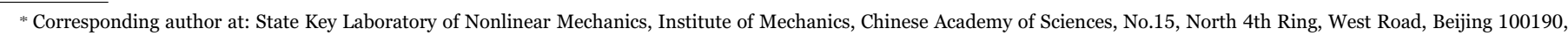
People's Republic of China.

E-mail addresses: xingjunxia@imech.ac.cn (J. Xing), fpyuan@lnm.imech.ac.cn (F. Yuan), xlwu@imech.ac.cn (X. Wu). 
(a)

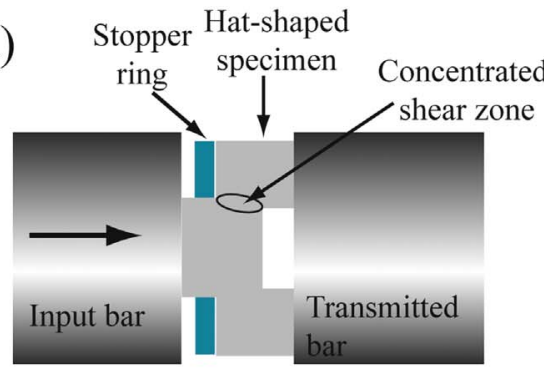

(b)

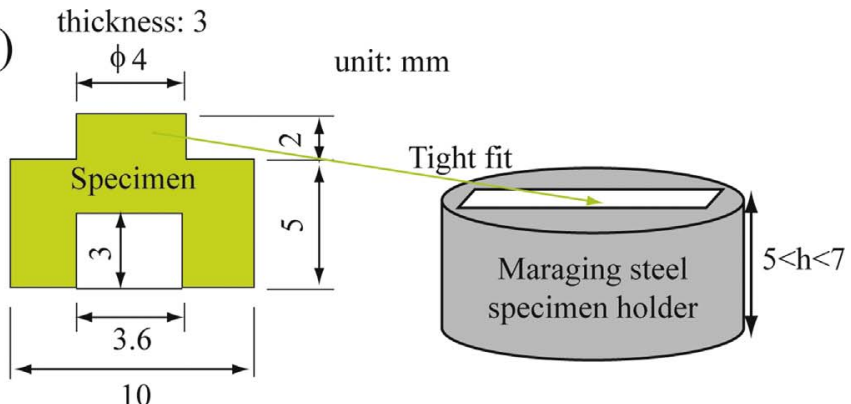

Fig. 1. (a) Hat-shaped specimen set-up in Hopkinson bar experiment; (b) Geometry and dimensions of hat-shaped specimen and specimen holder.

benefits from both gradient structure and TRIP effect. The resultant TRIP-gradient steel takes advantage of both mechanisms, allowing the TRIP effect to large plastic strain by triggering martensitic transformation successively along the depth through strain partitioning in the gradient structure [23]. So one of objectives in the present study is to produce high strength and ductility in 301 SS by combining several strain hardening mechanisms together, such as TRIP effect, strain partitioning and back stress hardening through GS and HLS.

For metals and alloys, the mechanical properties and the strain hardening behaviors during plastic deformation are well known to be highly dependent on the loading rate [24-27]. And the high strain rate $\left(10^{2} / \mathrm{s}\right.$ and above) behaviors of steels have great interests and concerns for applications as impact tolerant or crash relevant structures [28]. Different from quasi-static deformation, the generated heat from plastic work during the high strain rate deformation cannot be dissipated into the environment, the corresponding strain induced adiabatic temperature rise has been shown to have strong influences on the plastic behaviors and the microstructure evolutions of metals and alloys [29-32]. Previous studies have shown that the grain size (especially down to the UFG or NG regime) has high impact on the high strain rate plastic deformation, and a number of investigations have been dedicated to the high strain rate behaviors of UFG or NG metals in the past two decades [27,29-31,33-38]. However, most of previous studies on dynamic deformation of UFG or NG metals were based on relatively homogeneous microstructures, with a few on GS $[32,39]$. Thus, the second objective of the present study is to investigate the high strain rate plastic deformation behaviors in the 301 SS with GS or HLS, in which the microstructures are heterogeneous and hierarchical with the minimum size scale at the UFG or NG range.

\section{Experimental procedures}

\subsection{Materials and microstructural characterization}

In the present study, the as-received 301 SS were hot-rolled plates, with thickness of $3 \mathrm{~mm}$. The chemical composition was $0.017 \mathrm{C}, 0.15 \mathrm{~N}$, $0.15 \mathrm{Mo}, 0.52 \mathrm{Si}, 1.3 \mathrm{Mn}, 6.86 \mathrm{Ni}, 16.52 \mathrm{Cr}$, and the balance of Fe (all in mass \%). The hot-rolled plates were annealed at $900{ }^{\circ} \mathrm{C}$ for $30 \mathrm{~min}$ to obtain a CG structure. The GS in 301 SS samples with thickness of 1 or $3 \mathrm{~mm}$ were produced by the surface mechanical attrition treatment (SMAT), in which the sample surfaces were impacted at high speeds by high strength spherical steels (with diameter of $3 \mathrm{~mm}$ ) using highpower ultra-sound. The SMAT processing time was the same for both sides of each disk, which is varied from 3 to $30 \mathrm{~min}$. The other details concerning SMAT can be found elsewhere [40]. The CG plates with thickness of $3 \mathrm{~mm}$ were also cold rolled (CR) into sheets with the final thickness of 1 or $2 \mathrm{~mm}$, and the subsequent annealing treatments were conducted on the $\mathrm{CR}$ sheets at $580-680^{\circ} \mathrm{C}$ for $1 \mathrm{~h}$ followed immediately by water quenching. The microstructures before and after mechanical testing were examined by optical microscope (OM), electron backscattered diffraction (EBSD). The sample surfaces for OM and EBSD were first polished to 2000 grit and finally polished with
$0.25 \mu \mathrm{m}$ diamond paste and $0.05 \mu \mathrm{m} \mathrm{SiO} 2$ aqueous solution. Then the OM samples were etched by a solution of $5 \% \mathrm{FeCl} 3,30 \% \mathrm{HCl}$ and $65 \%$ $\mathrm{C} 2 \mathrm{H} 5 \mathrm{OH}$, and the EBSD samples were electro-polished by a solution of $10 \% \mathrm{HCLO}_{4}$ and $90 \%$ alcohol at $20 \mathrm{~V}$ voltage and $0{ }^{\circ} \mathrm{C}$ to reveal the microstructure. The spatial resolution of EBSD can be significantly improved through the use of a field emission gun and low accelerating voltage, and appropriate sample preparation by electro-polishing, making it possible to successfully explore even the microstructure evolution in the shear band [41,42]. All quasi-static tensile tests are on the plates with thickness of about $1 \mathrm{~mm}$, while all dynamic shear tests are on the plates with thickness of $2-3 \mathrm{~mm}$.

\subsection{Mechanical property tests}

Quasi-static tensile specimens were dog-bone shape plates with a thickness of about $1 \mathrm{~mm}$, a gauge length of $8 \mathrm{~mm}$, and a width of $2.5 \mathrm{~mm}$. Uniaxial tensile tests were carried out at a strain rate of $4 \times 10^{-3} / \mathrm{s}$ at room temperature by displacement control using an Instron 5565 testing machine. An extensometer was used to measure the strain during tensile testing.

All samples for dynamic shear testing were machined from the SMATed sheets or the sheets processed by CR plus annealing using wire saw with loading direction parallel to the CR direction. The hatshaped specimen set-up in Hopkinson bar experiment is shown in Fig. 1a, and the geometry and dimensions of the hat-shaped disks are given in Fig. 1b. The hat-shaped design has been a widely accepted method to investigate adiabatic shear band (ASB) in various metals $[27,31,43-48]$. In the hat-shaped specimens, the shear deformation is concentrated in a narrow zone facilitating the formation of ASB [43]. Since flatted specimens were used for dynamic shear testing, cylindrical specimen holders made of high strength maraging steel were used for two purposes: 1) guarantee a nearly pure shear deformation by constraining two legs of the hat-shaped specimens; 2) control the shear displacement by changing the height of the specimen holders. The other details for the Hopkinson-bar technique can be found in the previous research $[24,31,49]$, including the one-dimensional elastic stress wave theory, the methods of calculating for the shear stress, the shear displacement, the nominal shear strain and the nominal shear strain rate.

Micro-hardness measurements were also made on the polished sample surfaces using a Vickers diamond indenter at a load of 5-15 g for $15 \mathrm{~s}$ dwell time before and after mechanical testing. The light load ( $5 \mathrm{~g}$ ) is especially compatible with measurements within ASB which have width of about $10 \mu \mathrm{m}$. Five groups of measurements for each point were made, the average value was taken and the error bar was also provided.

\section{Results and discussions}

\subsection{Quasi-static tensile properties}

The CG austenitic structure annealed at $900{ }^{\circ} \mathrm{C}$ for $30 \mathrm{~min}$ is shown 

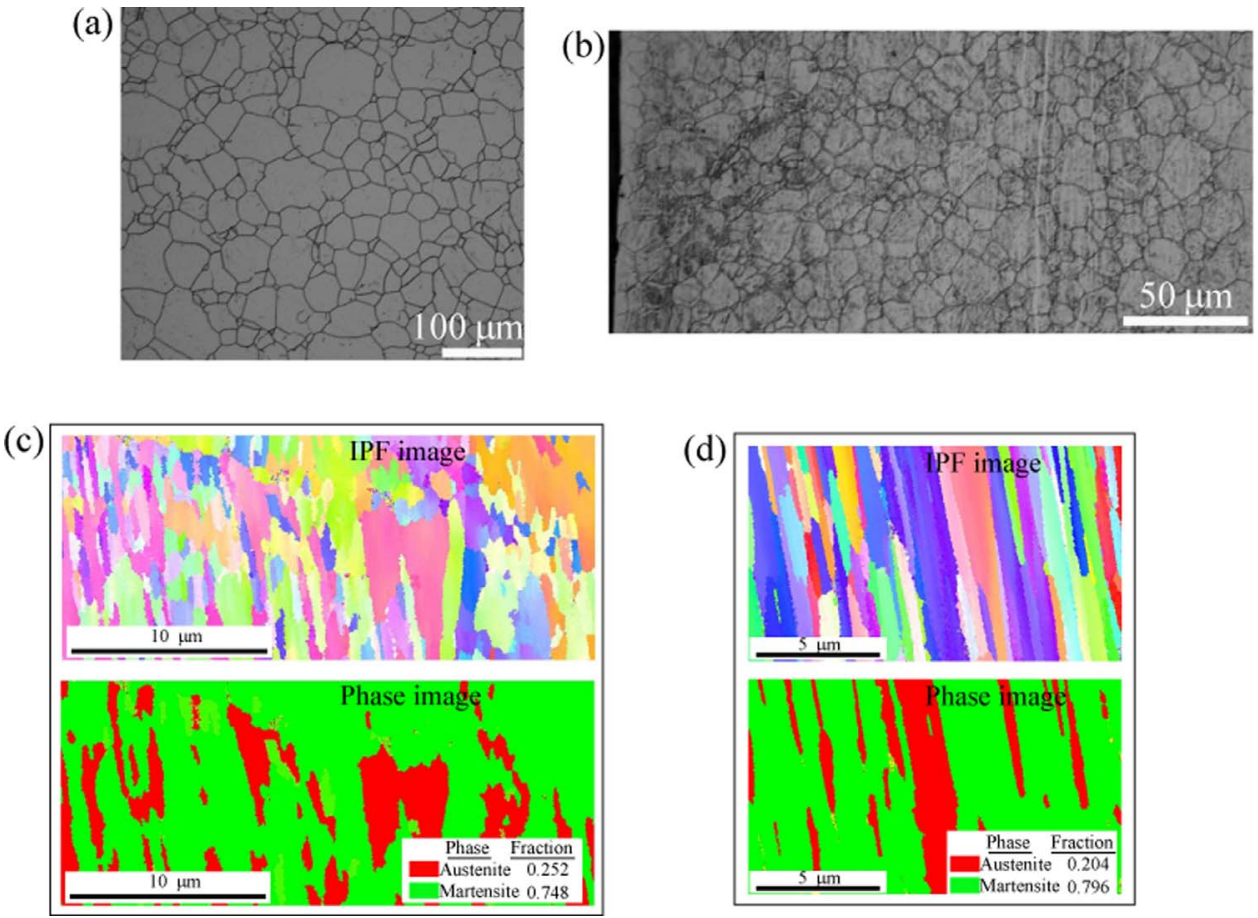

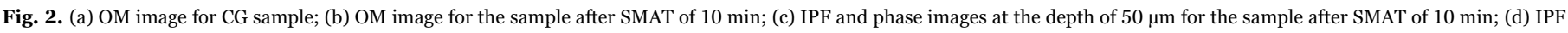
and phase images for the sample after CR followed by $660{ }^{\circ} \mathrm{C}$ annealing.

in Fig. 2a, and the average grain size is estimated to be about $37 \mu \mathrm{m}$. OM image for the sample after SMAT of $10 \mathrm{~min}$ is shown Fig. 2b, while images for inverse pole figure (IPF) and phase distribution at the depth of $50 \mu \mathrm{m}$ for the sample after SMAT of $10 \mathrm{~min}$ are shown in Fig. 2c. It is shown that the grain size near the surface is severely refined to about $500 \mathrm{~nm}$ with elongated shape, and about 3 quarters of austenite are transformed into martensite by the severe plastic deformation during the SMAT. IPF and phase images for the sample after CR followed by $660{ }^{\circ} \mathrm{C}$ annealing are shown in Fig. $2 \mathrm{~d}$, and it is interesting to note that the microstructure is a HLS with lamellar thickness of about $500 \mathrm{~nm}$. In this HLS, both austenite and martensite are lamellar shapes, and the martensite phase is with a fraction of nearly $80 \%$.

Fig. 3 shows the quasi-static tensile properties of 301 SS with various microstructures. Fig. $3 \mathrm{a}$ and $\mathrm{b}$ display the engineering stress versus engineering strain curves for GS and HLS, respectively. Fig. 3c and $d$ show the strain hardening rate and the true stress as a function of true strain for samples with GS and HLS, respectively. All samples with GS show similar stress-strain curves to that of CG, and the yield strength increases while the uniform elongation decreases with increasing SMAT time. In our recent research [23], we proposed that the resultant TRIP-gradient 304 steel takes advantage of both gradient effect and TRIP effect, allowing the martensitic transformation to last to large strains. The stress-strain behaviors for gradient $301 \mathrm{SS}$ in the present study are very similar to those for gradient 304 SS [23], thus the resultant TRIP-gradient $301 \mathrm{SS}$ in the present study also have good combination of strength and ductility. The stress-strain curves for the samples with HLS show three different yielding and plastic flow behaviors: 1) yield drop followed by necking for CR samples; 2) yield drop followed by a strain hardening rate up-turn and then necking for samples annealed at $580-640{ }^{\circ} \mathrm{C}$; 3) strain hardening rate up-turn followed by necking for samples annealed at $660-680^{\circ} \mathrm{C}$. For CR samples, the strain hardening rate and the uniform elongation are low due to the absence of the martensitic transformation, resulting in the first yielding and flow behavior. For samples annealed at $580-640{ }^{\circ} \mathrm{C}$, the yield drop is due to a lack of mobile dislocation density, and the following up-turn for strain hardening rate is due to the a small amount of martensitic transformation. For samples annealed at $660-680^{\circ} \mathrm{C}$, the austenite phase obtained during annealing is enough to provide adequate martensitic transformation and sustain a high strain hardening rate by an apparent up-turn without yield drop. As a summary of the quasi-static tensile properties measured in the present study for $301 \mathrm{SS}$, Fig. 3f plots yield strength versus uniform elongation curves for GS and HLS. The synergy of GS and HLS is better than the typical banana curve, and shows a good combination of strength and ductility, which is due to the strain partitioning, the strain gradient and the back stress hardening for heterogeneous structures $[6,23,50]$.

Fig. 4a and b display Vickers micro-hardness distributions along the depth for the samples after SMAT of various times before and after tensile tests, respectively. The hardness for the untreated CG 301 SS is also plotted as a straight dash line in Fig. 4a for comparison. Fig. 4d displays Vickers micro-hardness distributions along the depth for the samples after CR followed by annealing at various temperatures before and after tensile tests. The standard deviations are plotted as error bars in Fig. 4a, b and c. As indicated, the micro-hardness decreases from about $390 \mathrm{Hv}$ at the top surface to about $290 \mathrm{Hv}$ at the center (very similar to the $287 \mathrm{Hv}$ for the untreated CG) for the SMATed samples with $3 \mathrm{~min}$. The gradient of hardness along the depth should be due to the gradient strain induced by the SMAT process. The hardness at each depth also increases with increasing process time of SMAT, as shown in Fig. 4a. As shown Fig. 3a and c, the 304 SS with GS show apparent strain hardening behaviors for the samples after SMAT of various times, we are wondering where contributes most to the observed overall strain hardening behaviors? To answer this question, the hardness increments along the depth after tensile testing are plotted in Fig. 4c for SMATed samples. As indicated, the hardness shows an increment at all depths after tensile testing, while the most strong hardness increment is observed at the center. The hardness increment is an indicator on the magnitude of hardening retained after unloading, so the center part contributes most to the overall strain hardening of SMATed samples, and the corresponding microstructures before and after tensile testing for the center part are presented in the Fig. 5. Fig. 5 shows the IPF and phase images at the center for the sample after SMAT of $10 \mathrm{~min}$. The grain size at the center is not changed after SMAT process, however the martensite phase is increased from $0-25 \%$ 


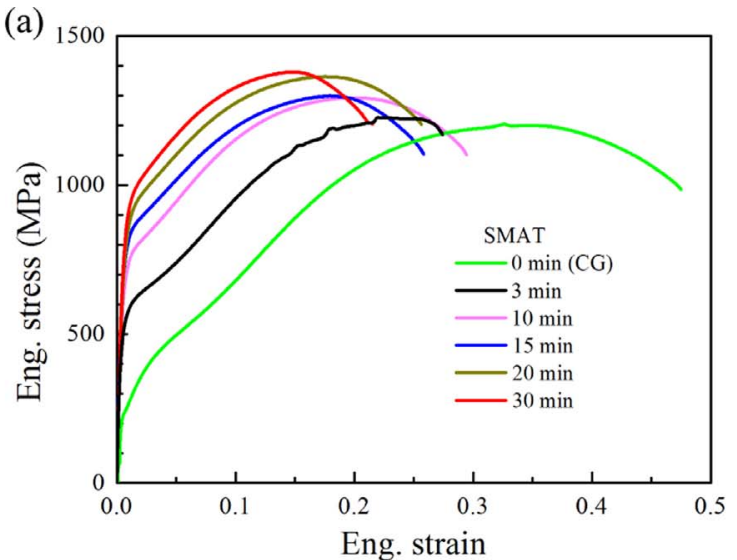

(c)

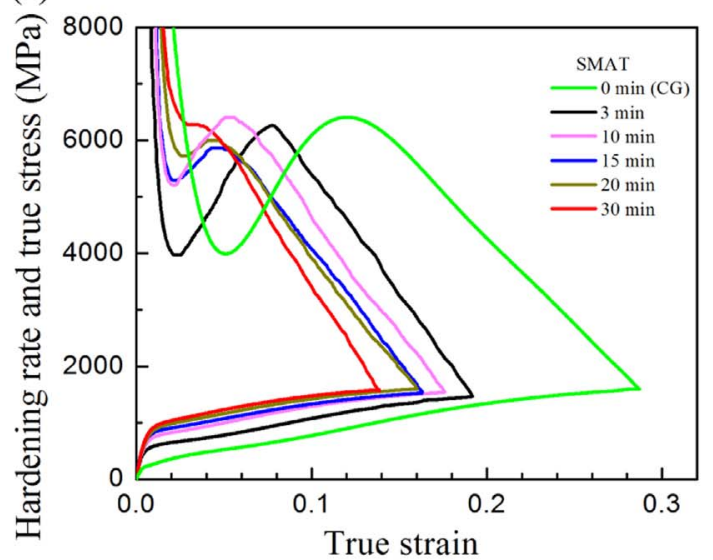

(b)

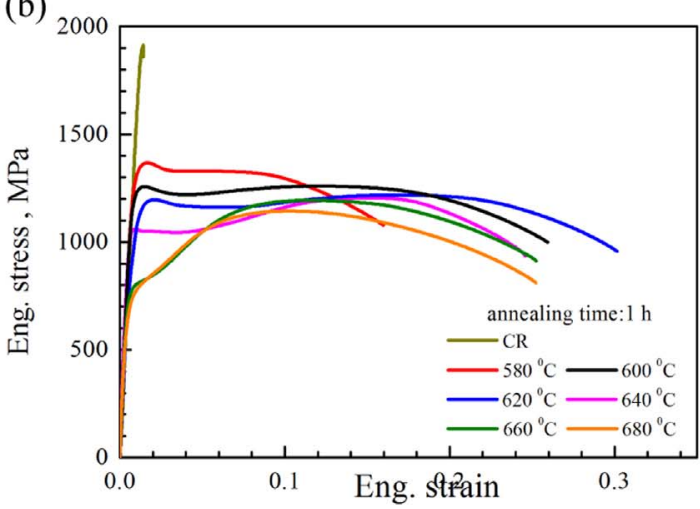

(d)

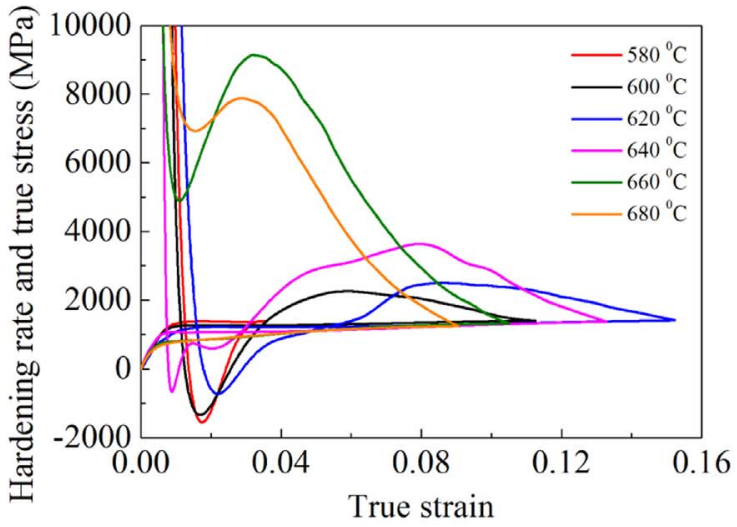

(f)

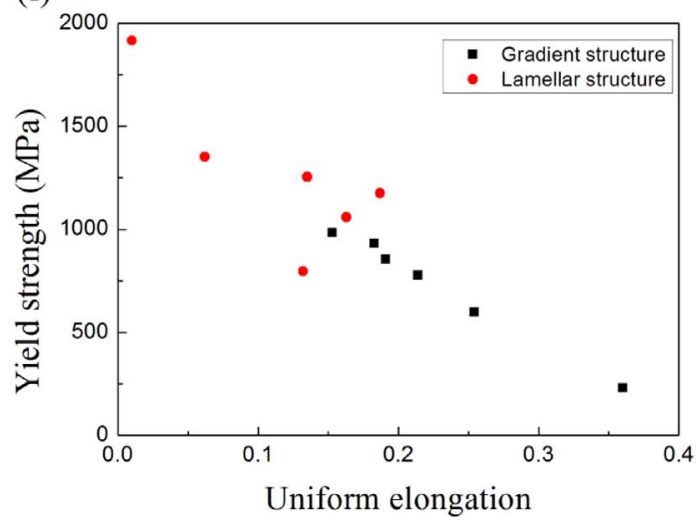

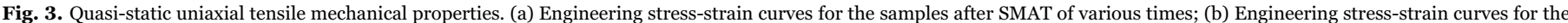

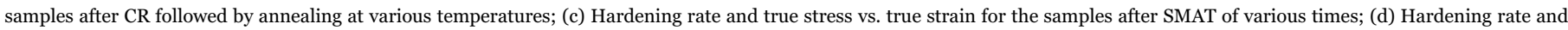

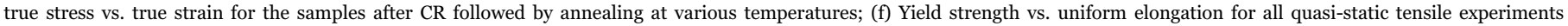
conducted in the present study.

after SMAT, resulting in a higher hardness (about $325 \mathrm{Hv}$ ) at the center than that of the untreated austenitic CG $(287 \mathrm{Hv})$. After tensile testing, the most austenite grains are transformed and the martensite phase is significantly increased from 25-95\%, resulting in a substantial hardness increment (from about $325 \mathrm{Hv}$ to about $460 \mathrm{Hv}$ ) at the center. These microstructure observations suggest that the martensitic transformation at the center contributes most to the overall strain hardening of GS although the martensitic transformation still occurs at other depths for small amount of strain hardening. For the HLS processed by CR followed by annealing at different temperatures, strong strain hardening indicated by hardness increment after tensile testing is also observed (Fig. 4d), which indicates that the martensitic transformation still takes place for strain hardening in these HLS.

\subsection{Dynamic shear response and ASB evolutions}

First, a series of Hopkinson-bar experiments with hat-shaped specimens were conducted to investigate the dynamic shear response and the ASB evolution mechanisms in the annealed CG austenitic structure. The dynamic shear process was interrupted at four different shear displacements by adjusting the height of the specimen holder, and then the microstructures at these displacements were "frozen" for subsequent observations. Fig. 6a displays the shear stress versus the shear displacement curves of the annealed CG austenitic samples for 
(a)

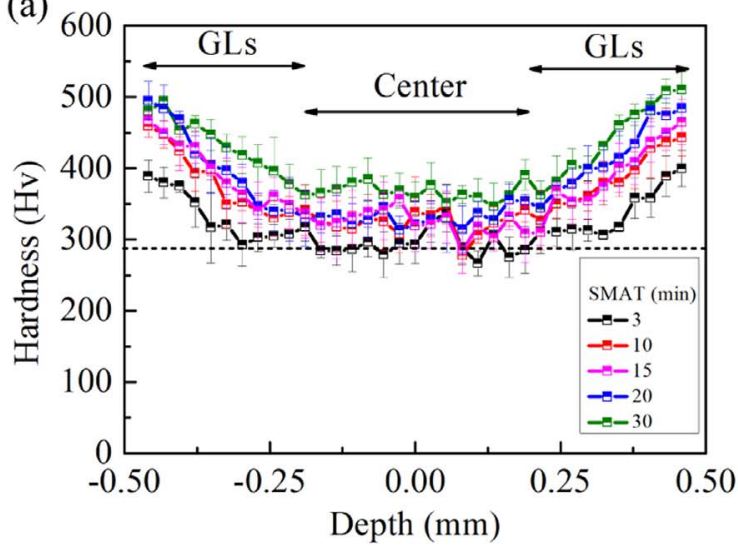

(c)

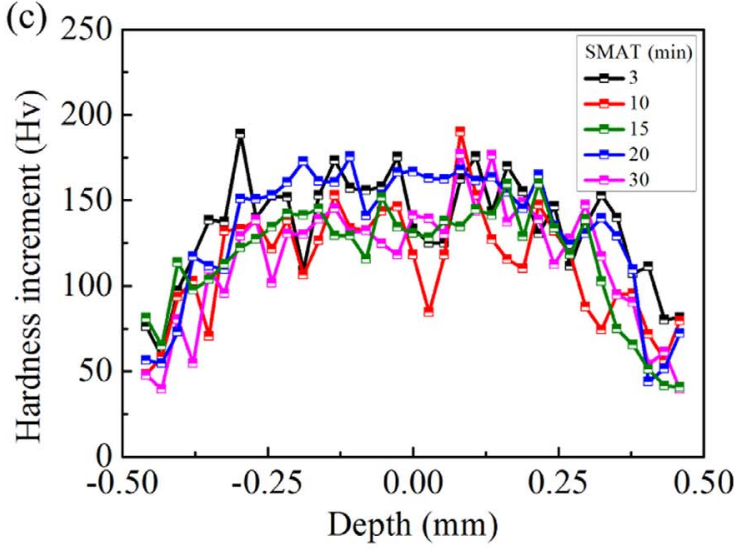

(b)

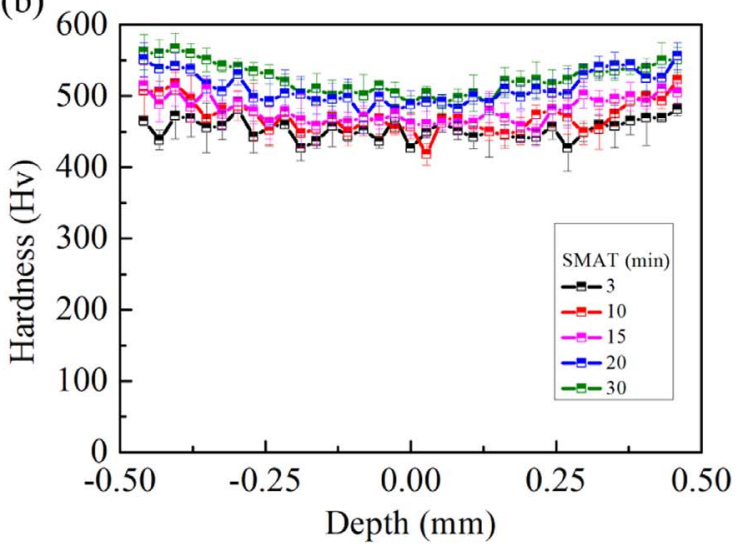

(d)

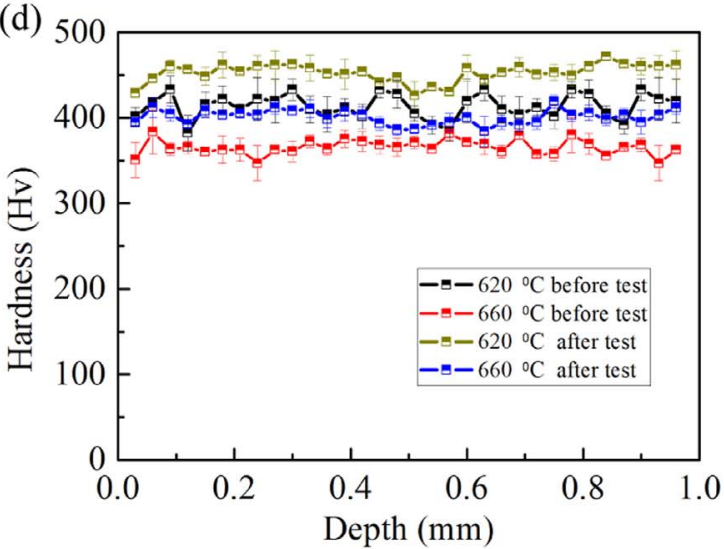

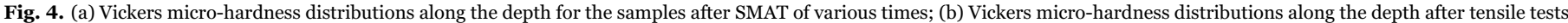

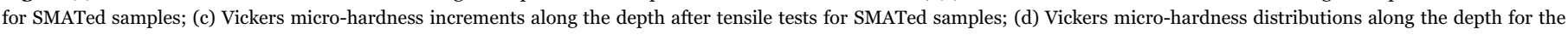
samples after CR followed by annealing at various temperatures before and after tensile tests.

the experiments with four interrupted displacements. In the analysis of ASB, it has been widely accepted that the peak point in the stressdisplacement curves is generally considered as the initiation point of the instability in terms of the maximum stress criterion $[27,31,44,46,48]$, after which ASB begins to form and evolve. The shear deformation is homogeneous in the concentrated shear zone before the formation of ASB, thus the nominal shear strain can be calculated through dividing the shear displacement by the width of the shear zone before the stress drop. Then, the shear stress versus the nominal shear strain curves for the annealed CG austenitic samples are shown in Fig. 6b. These curves show four different stages under dynamic shear loading: 1) the elastic stage; 2) the strong linear hardening stage; 3 ) the plateau stage; 4) the stress drop stage for ASB evolution [27,31,44,46,48]. It has been proposed that the strong linear hardening stage is mainly due to the martensitic transformation, while the plateau stage is due to the competition between the thermal softening and the hardening from the continuous deformation through strain partitioning between different phases for a 5Mn TRIP steels in our recent paper [31]. The similar behaviors observed in the present study should be due to the similar operating mechanisms. Finally, the experienced homogeneous shear strain is estimated to be about 4.0 for the fully austenitic CG structure.

With controlled shear displacements, the microstructure evolution in the shear zone can be well characterized. OM images of the concentrated shear zone at three different interrupted displacements $(0.60,1.35$ and $1.80 \mathrm{~mm})$ are shown in Fig. 7. All upper ends are the hat ends, while all bottom ends are base ends in these figures. As indicated, the shear deformation is not enough to form ASB when the shear displacement is as small as $0.60 \mathrm{~mm}$. The OM image in Fig. $7 \mathrm{a}$ shows that the CG grains are slightly sheared without formation of
ASB. The point at the stress drop is assumed to be the onset of ASB according to the maximum stress criterion $[27,31,44,46,48]$, thus the critical shear displacement and the critical shear strain for the onset of ASB should be around $0.80 \mathrm{~mm}$ and 4.0 , respectively, based on the dynamic shear curves in Fig. 6 . In Fig. $7 \mathrm{~b}$ and c, thin localized thin bands are clearly observed when the shear displacements (1.35 and $1.8 \mathrm{~mm})$ are large than the critical shear displacement $(\sim 0.80 \mathrm{~mm})$. In the areas adjacent to the ASB, the CG grains are also severely sheared. Cracks are also observed to nucleate and propagate along the ASB from both ends once ASB is formed, and the crack lengths are observed to increase with increasing shear displacement. These cracks are due to the severe shear deformation and the high temperature rise within ASB during the shear deformation.

The deformation process in the shear zone ( $200 \mu \mathrm{m}$ width) can be considered as an adiabatic process, and the temperature rise due to the plastic deformation within the shear zone can be estimated by the following equation [47]:

$\Delta T=\frac{\eta}{\rho C_{v}} \int_{\varepsilon_{s}}^{\varepsilon_{e}} \sigma d \varepsilon$

where $\eta$ is the coefficient of plastic work converted to heat (commonly $\eta=0.9$ ), $\rho$ is the mass density, $C_{v}$ is the heat capacity, $\varepsilon$ is the strain, and $\sigma$ is the stress. For SS, $\rho$ is $7.9 \mathrm{~g} / \mathrm{cm}^{3}$ and $C_{v}$ can be taken as $500 \mathrm{~J} /$ $\mathrm{kg}[46]$.

Substituting the dynamic shear response data in Fig. 6b into Eq. (1), the adiabatic temperature rise in the shear zone up to the point at the stress drop (corresponding to the onset of ASB) can be estimated to be about $540 \mathrm{~K}$. However, once ASB is formed, the shear deformation in the shear zone is no longer homogeneous, and the subsequent shear deformation will be mainly carried by the thin shear band (about 10- 

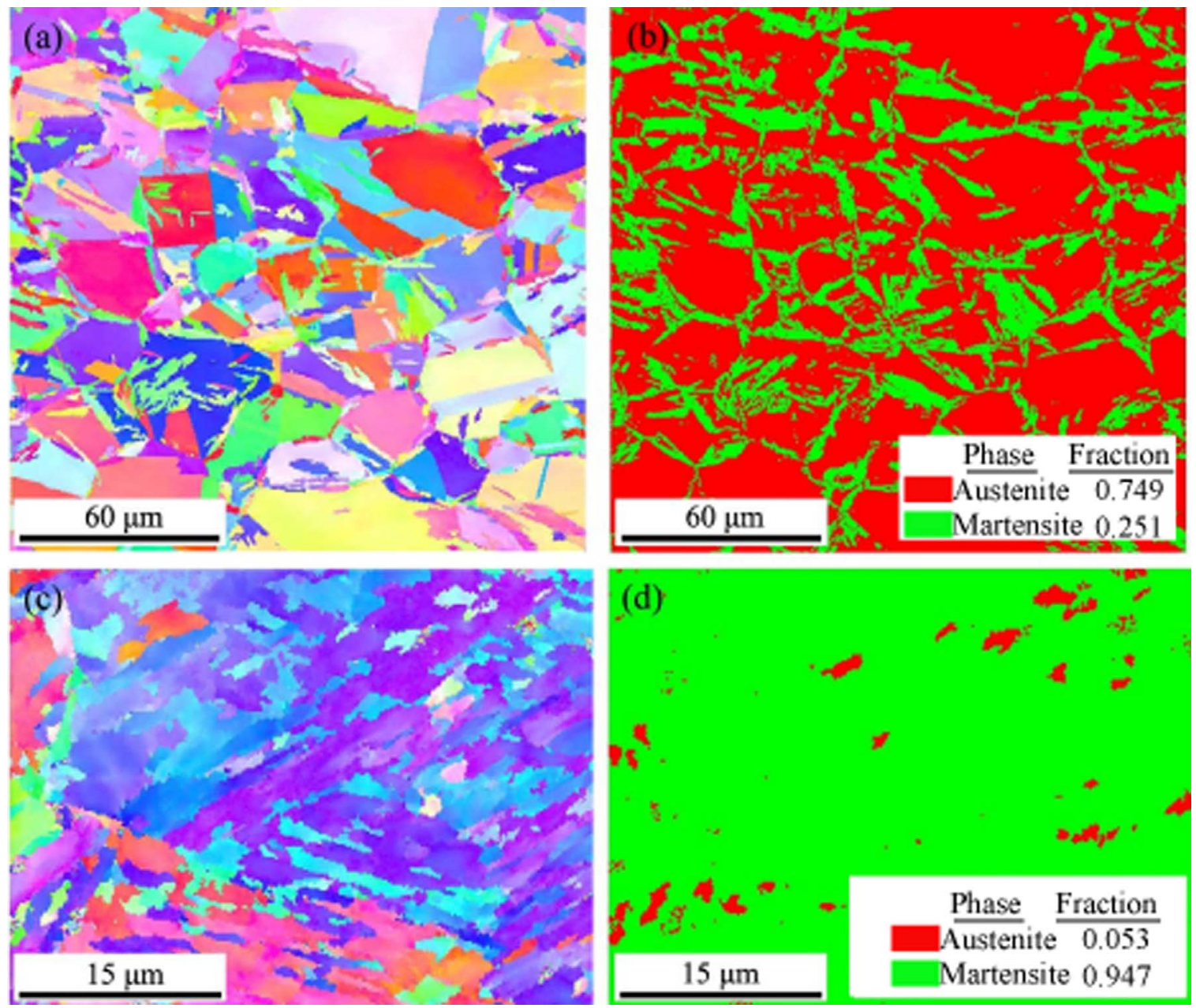

Fig. 5. IPF and phase images at the center for the sample after 10 min SMAT: (a) (b) before tensile tests; (c) (d) after tensile tests.

$20 \mu \mathrm{m}$ width). Thus, the shear deformation magnitude within the ASB would be much higher than the nominal shear strain shown in Fig. $6 \mathrm{~b}$ (about 4.0). Due to this high shear strain within the ASB, the temperature rise within the ASB can be easily close to or even higher than one thousand degree although the exact temperature rise within the ASB can't be calculated because the shear deformation within the shear zone is no longer homogeneous after stress drop point and the width of ASB is changing with increasing shear displacement.
The Vickers micro-hardness distributions traversing the concentrated shear zone at three different interrupted shear displacements $(0.60,1.35$ and $1.80 \mathrm{~mm})$ are displayed in Fig. 8. When the shear displacement is small $(0.60 \mathrm{~mm})$, the shear deformation is not enough to form ASB (as shown in Fig. 7), which can also be further identified by the hardness distribution where no obvious peak is observed at the shear displacement of $0.60 \mathrm{~mm}$ in Fig. 8. However, an obvious hardness increment is still observed compared to that of un-deformed
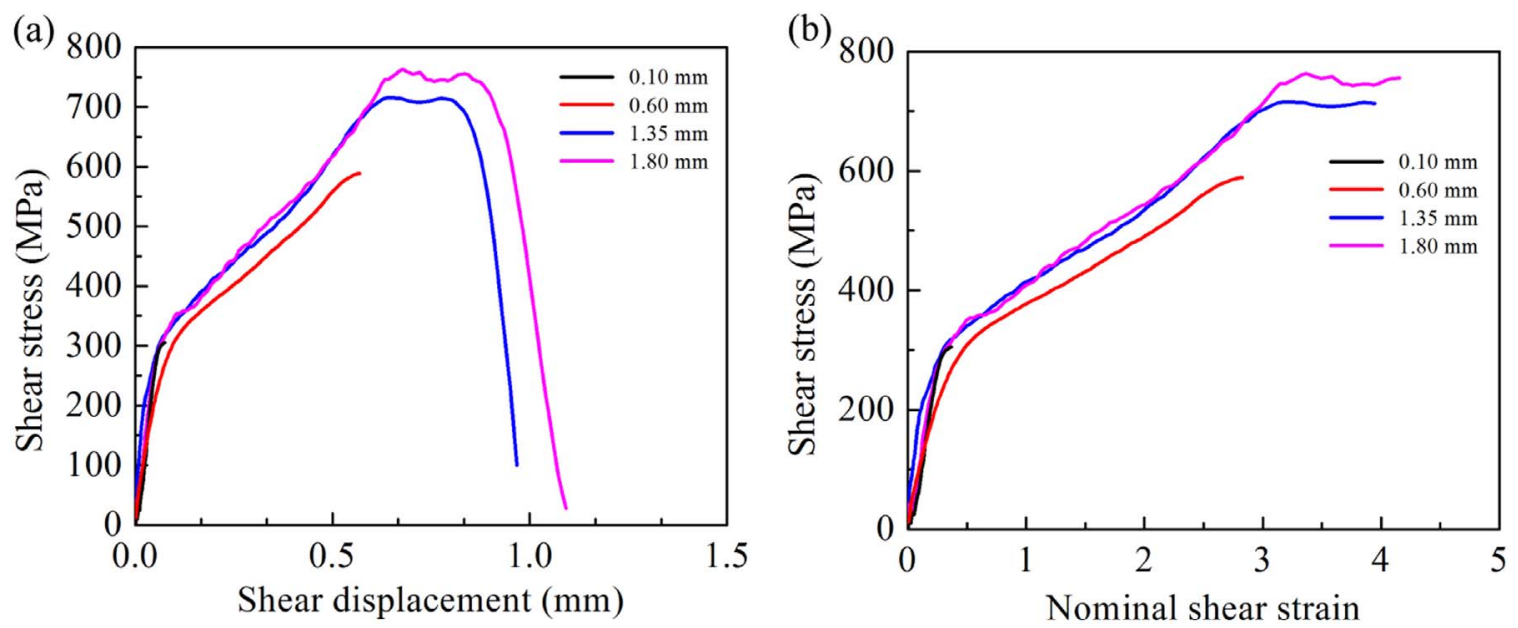

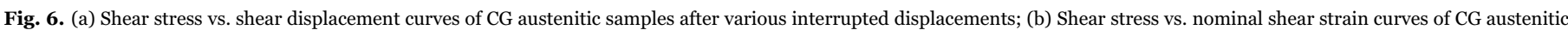
samples after various interrupted displacements. 
(a)

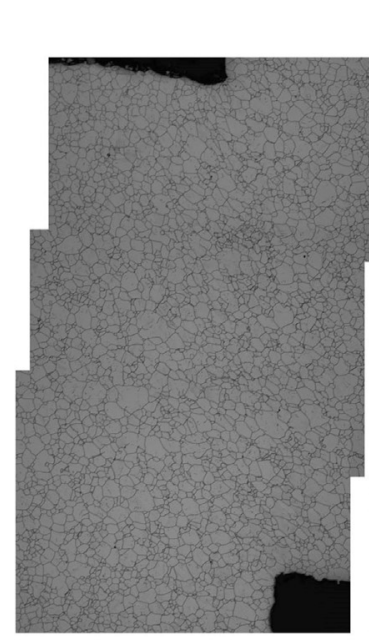

$1.0 \mathrm{~mm}$ (b)

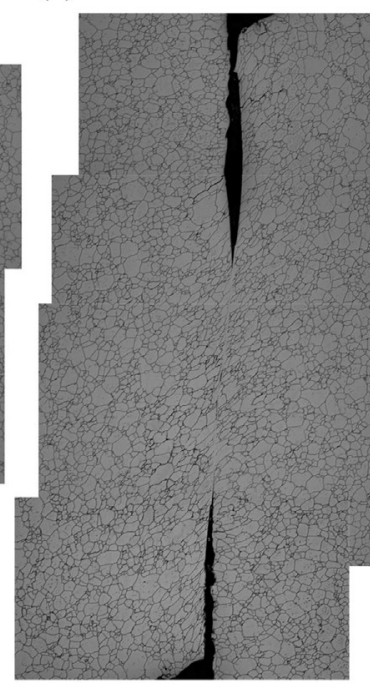

$1.0 \mathrm{~mm}$ (c)

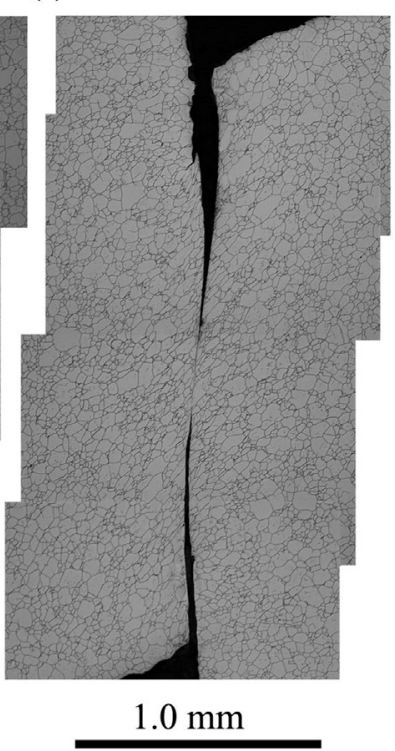

Fig. 7. OM images for ASB evolution in the CG austenitic samples observed at three different interrupted displacements: (a) $0.60 \mathrm{~mm}$; (b) $1.35 \mathrm{~mm}$; (c) $1.80 \mathrm{~mm}$.

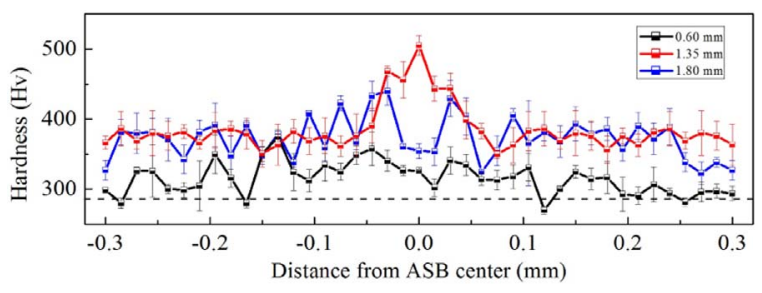

Fig. 8. Vickers micro-hardness distributions traversing the ASB at three different interrupted displacements for the CG austenitic samples. The initial hardness for the un-deformed matrix is also given by a dashed line.

CG austenitic matrix due to the martensite transformation by the homogeneous shear deformation at the shear displacement of $0.60 \mathrm{~mm}$. An obvious hardness peak is observed at the shear displacement of $1.35 \mathrm{~mm}$, indicating the formation of ASB, while an obvious valley is shown at the center of the shear zone with shear displacement of $1.80 \mathrm{~mm}$. Moreover, the hardness outside the ASB further increases with increasing shear displacement.

The corresponding microstructure evolution at the area of ASB will be provided here to explain the hardness distributions displayed in Fig. 8. Fig. 9 shows IPF images of the ASB areas at two different interrupted displacements $(1.35$ and $1.80 \mathrm{~mm}$ ) for the $\mathrm{CG}$ austenitic samples. The width of ASB is observed to increase with increasing shear displacement, this thickening trend of ASB along with shear deformation was also observed in other metals and alloys [31,48]. It is shown that the grains in the ASB are clearly refined and equiaxed when compared to the band structure of the surrounding area with larger grains. From the corresponding close-up views (Fig. 9c and d), it is shown that the average grain size in the ASB increases slightly from $\sim 250$ to $\sim 400 \mathrm{~nm}$ when the shear displacement increases from 1.35 to $1.80 \mathrm{~mm}$, this could be due to the high temperature rise in the ASB. Phase images of the ASB areas at two different interrupted displacements (1.35 and $1.80 \mathrm{~mm}$ ) for the CG austenitic samples are displayed in Fig. 10. The austenite phase is displayed by red color, while the martensite phase is displayed by green color. Outside the ASB, the fraction of austenite phase is much reduced by martensite transformation through homogeneous shear deformation. However, the fraction of martensite phase in the ASB is decreased when compared to the surrounding area due to the inverse transformation (martensite to austenite transformation), which also could be due to the high temperature rise in the ASB. It is shown that the inverse transforma-
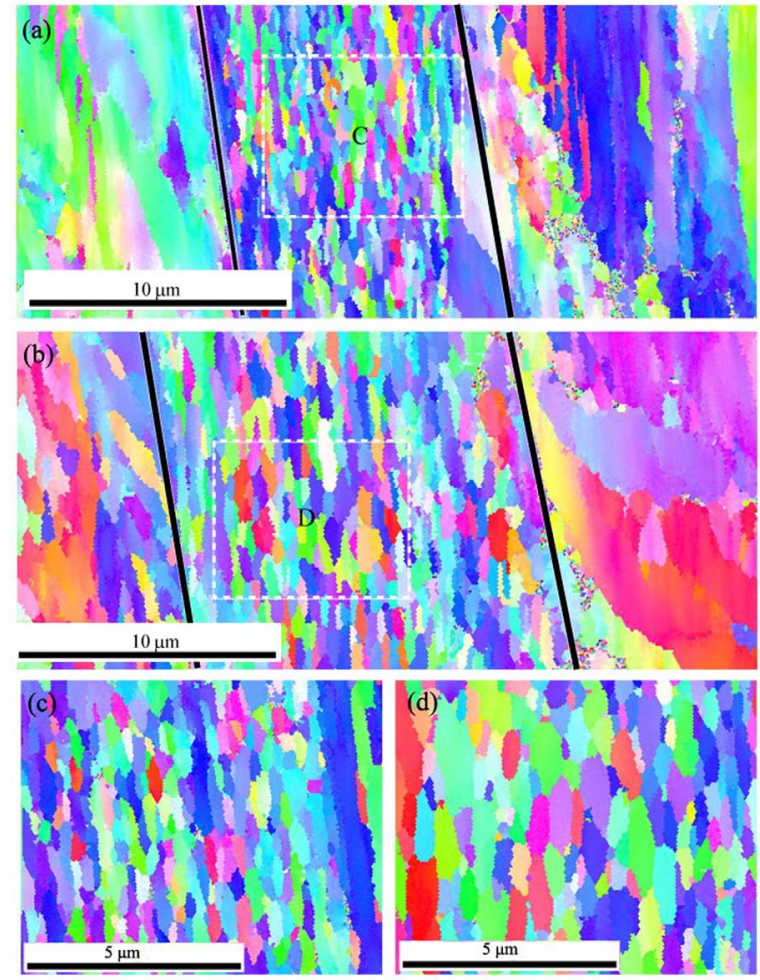

Fig. 9. IPF images of the ASB areas at two different interrupted displacements for the CG austenitic samples: (a) $1.35 \mathrm{~mm}$; (b) $1.80 \mathrm{~mm}$. (c) (d) The corresponding close-up views for the rectangular areas in (a) and (b).

tion continues within the ASB with increasing shear displacement, and the fraction of martensite phase is further reduced within the ASB when the shear displacement increases from 1.35 to $1.80 \mathrm{~mm}$. These interesting observations for austenite phase distribution in the surrounding area and within the ASB, and the evolution with increasing shear displacement, are actually due to the competition between the martensite transformation induced by shear deformation and the inverse transformation caused by the high temperature rise followed by rapid quench after the deformation. These interesting observations for the grain size and the austenite phase distributions within the ASB 


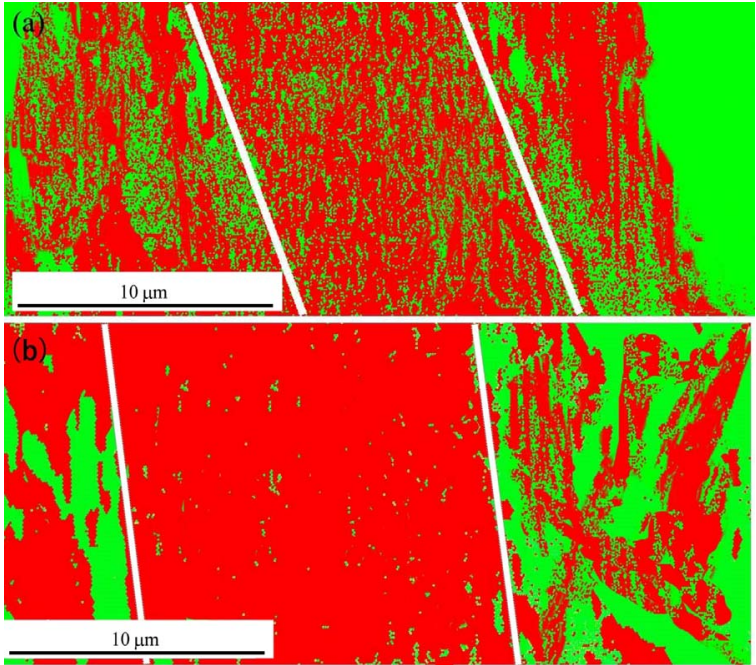

Fig. 10. Phase images of the ASB areas at two different interrupted displacements for the CG austenitic samples: (a) $1.35 \mathrm{~mm}$; (b) $1.80 \mathrm{~mm}$. The red area is for austenite phase, while the green area is for martensite phase. (For interpretation of the references to color in this figure legend, the reader is referred to the web version of this article.).

and in the surrounding area, along with the evolutions of these microstructures with increasing shear displacement, also correlate very well with the micro-hardness distributions and evolution observed in Fig. 8.

As shown in Fig. 3, the 301 SS with GS and HLS show a good combination of strength and ductility due to the back stress hardening for heterogeneous structures $[6,23,50]$. Thus, the dynamic shear responses of the 301 SS with GS and HLS were investigated by hatshaped experiments. Fig. 11a and $\mathrm{c}$ show the shear stress versus the shear displacement curves of the GS after SMAT of various times and the HLS after CR followed by annealing at various temperatures, respectively. Fig. $11 \mathrm{~b}$ and d display the shear stress versus the nominal shear strain curves of the GS after SMAT of various times and the HLS after CR followed by annealing at various temperatures, respectively. As indicated, the strong linear hardening stage for the annealed CG austenitic structure is not observed for the 301 SS with GS and HLS, which indicates that the martensite transformation is not as strong as the CG austenitic structure. The 301 SS with GS and HLS only show slightly strain hardening while still display substantial uniform shear deformation before the formation of ASB. The magnitude of the uniform shear deformation decreases with increasing SMAT times, while the annealing temperature seems to have little effect on both the dynamic shear yield strength and the uniform shear strain.

The dynamic shear toughness can be obtained from the area under the shear stress versus shear strain curves in Figs. $6 \mathrm{~b}$ and $11 \mathrm{~b}$ and $\mathrm{d}$. The dynamic shear toughness is an indicator of energy absorption under impact conditions, and the materials with both high strength and high impact toughness can be considered as excellent candidates for energy absorbers or impact-tolerant structures, such as in the automotive industry. The impact shear toughness under impact conditions as a function of dynamic shear yield strength is displayed in Fig. 12 for the 301 SS with CG austenitic structure, GS and HLS. The CG austenitic structure has the lowest dynamic shear yield strength while has the highest impact shear toughness. The HLS seems to have better impact shear properties than the GS, and the reasons could be following. As we know, the GS have the inhomogeneous microstructure along the depth, thus the heterogeneity exists macroscopically between different layers along the depth, and the ASB could be formed first in the hardest layer at the surface and then propagates along the depth into the center. As indicated in the previous work [46], ASB generally initiates right after yielding for the homogeneous metals with deformed structure (pre-shocked). However, the formation of ASB for the treated surface layer in the gradient structure seems to be delayed due to the strain gradient and the interaction between different layers in the gradient structure, as indicated in the shear stress-strain curves of Fig. 11b. In order to verify this and illustrate where the ASB is formed first and how the ASB propagates in the gradient structure, several interrupted dynamic shear experiments and subsequent careful microstructure observations for the treated surface, the CG center and the cross-section along the depth in the gradient structure need be done, and these detailed investigations will be provided in the future work. While, the heterogeneity only exists microscopically in the HLS, thus the soft domain could delay the formation of the ASB in the adjacent hard domain. Moreover, the GS and HLS show good dynamic shear properties, in which the dynamic shear yield strength is more than 2 or 3 times of that of CG austenitic structure while the dynamic shear toughness is more than half of that of CG austenitic structure, this could be due to the back stress hardening for either macroscopically or microscopically heterogeneous structures $[6,23,50]$.

OM images of the ASB area after $1.8 \mathrm{~mm}$ shear displacement for the samples after $\mathrm{CR}$ followed by $580^{\circ} \mathrm{C}$ annealing and for the samples after CR followed by $620^{\circ} \mathrm{C}$ annealing are displayed in Fig. 13a and b, respectively. The corresponding close-up views of the ASB, along with the close-up view of the ASB for the CG austenitic structure, are shown in Fig. 13c, d and e, respectively. Cracks are also observed to nucleate and propagate along the ASB from both ends once ASB is formed for the HLS, and the crack lengths (about $1 \mathrm{~mm}$ ) are observed to be similar to that of the CG structures. Thin localized shear bands are clearly observed for three cases when the shear displacement is around $1.8 \mathrm{~mm}$, and the width of the ASB (about $10 \mu \mathrm{m}$ ) for HLS is slightly smaller than that of the CG austenitic structure (about $17 \mu \mathrm{m}$ ). This indicates that the shear deformation is more concentrated in the HLS due to the lower strain hardening ability than the CG austenitic structure.

The following equation for calculating the width of ASB was proposed based on perturbation analysis of the uniform solutions to the governing equation of ASB [51]:

$\delta \approx 2\left(\frac{k T}{\tau \dot{\gamma}}\right)^{1 / 2}$

where $k$ is the thermal conductivity, $T, \tau, \dot{\gamma}$ are the temperature, the shear stress and the shear strain rate within the ASB, respectively. For steels, $k$ can be approximately taken as $60 \mathrm{~W} /(\mathrm{K} \mathrm{m})$ [31].

The shear stress at the maximum stress point from Figs. $6 \mathrm{~b}$ and $11 \mathrm{~d}$ can be used to estimate the width of ASB. The nominal shear strain rate in the shear zone can be obtained from the strain gage signal of the reflected wave, while the actual shear strain rate within the ASB should be at least 10 times higher than the nominal shear strain rate [31]. The temperature within the shear zone can be estimated by Eq. (1) and the data from Figs. $6 \mathrm{~b}$ and $11 \mathrm{~d}$. However, as we mentioned earlier, the actual temperature within ASB should be much higher than that calculated from Eq. (1), thus we take $1000^{\circ} \mathrm{C}(1273 \mathrm{~K})$ as the temperature within ASB for a rough estimation of ASB width. Assuming the shear strain rate within ASB to be 10 times of the nominal shear strain rate, the widths of ASB have been roughly estimated to be in the range of $20-30 \mu \mathrm{m}$ for the CG austenitic structure and HLS. There is a relatively well agreement between experimental results $(10-17 \mu \mathrm{m})$ and theoretical prediction (20$30 \mu \mathrm{m})$ since Wright [52] mentioned that the agreement of Eq. (2) with experimental results is usually within a factor 2 .

Fig. 14 shows the Vickers micro-hardness distributions traversing the ASB at $1.8 \mathrm{~mm}$ shear displacement for the samples after CR followed by $580^{\circ} \mathrm{C}$ annealing and for the samples after CR followed by $620^{\circ} \mathrm{C}$ annealing. Obvious peaks are observed for both cases, indicating substantial hardness increments in the ASB. This situation is totally different from the case at $1.8 \mathrm{~mm}$ shear displacement for the CG austenitic structure, where an obvious valley is observed due to the 

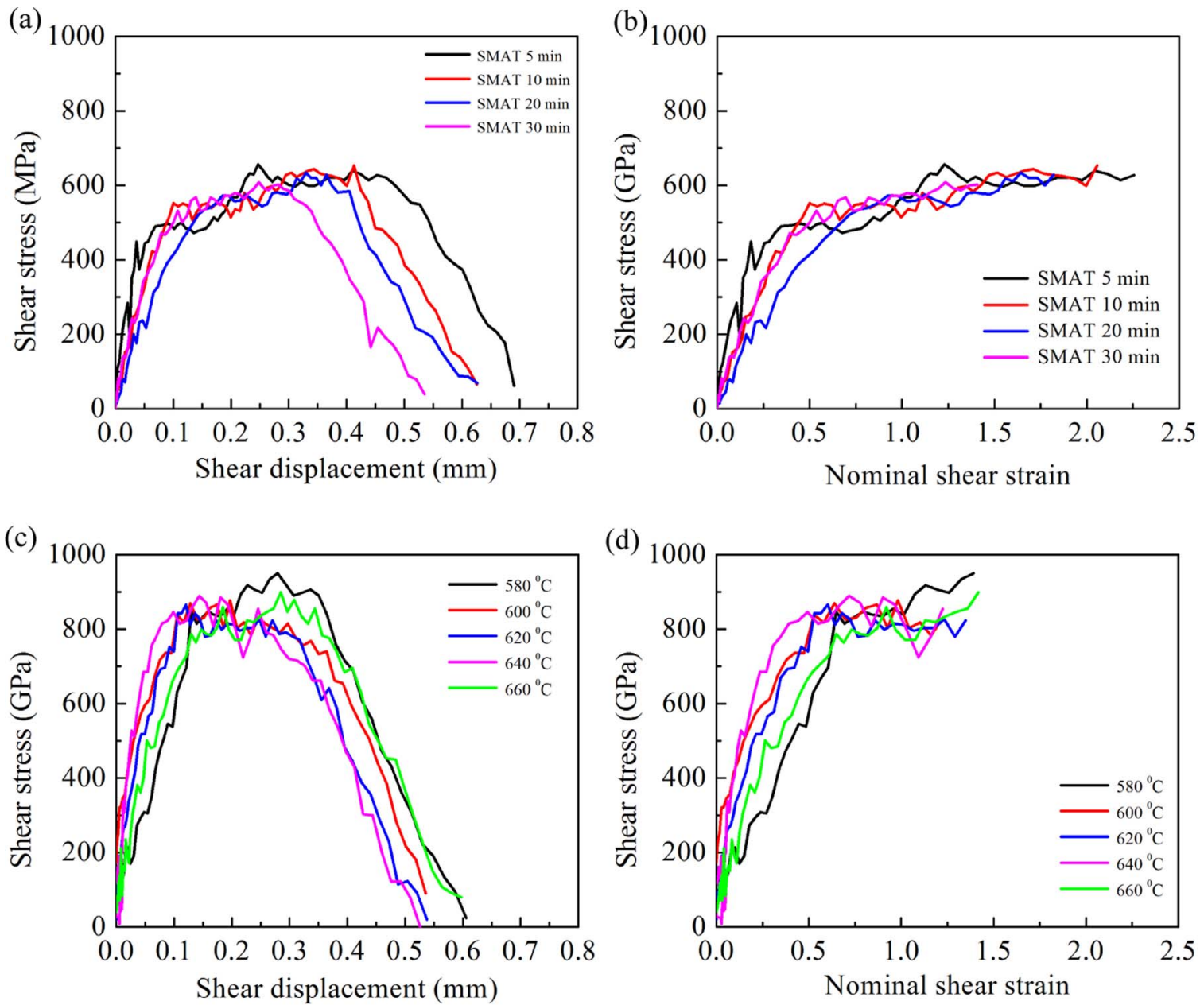

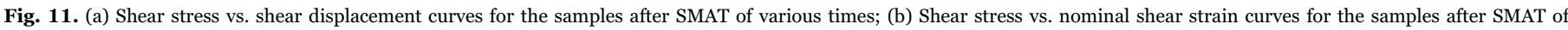

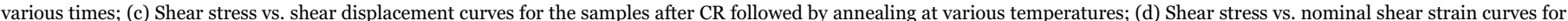
the samples after CR followed by annealing at various temperatures.

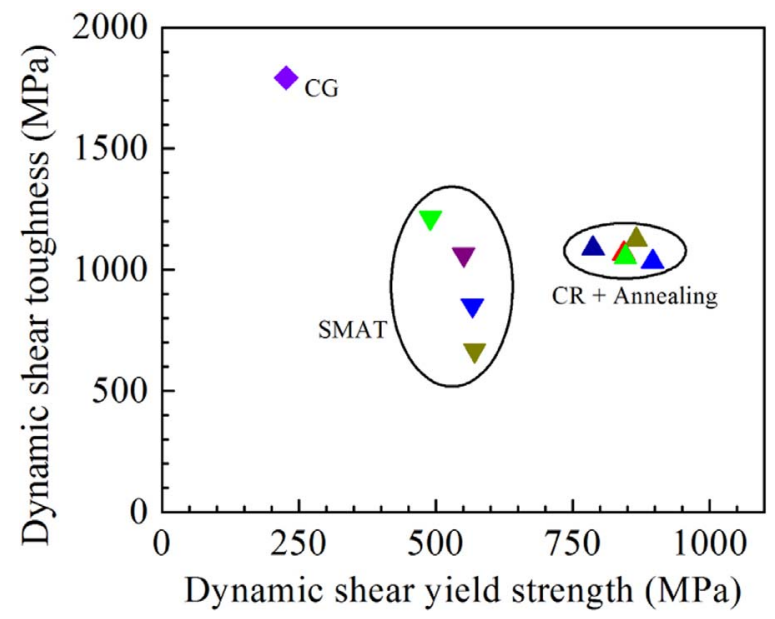

Fig. 12. Impact shear toughness vs. dynamic shear yield strength for the experiments conducted in the present study.

almost complete disappear of the martensite phase in the ASB. Thus, IPF and phase images of the ASB area after $1.8 \mathrm{~mm}$ shear displacement for the samples after $\mathrm{CR}$ followed by $620^{\circ} \mathrm{C}$ annealing are also provided and are shown in Fig. 15. As indicated, the grains in the ASB for HLS are much refined to equiaxed grains with a grain size of about $200 \mathrm{~nm}$. As indicated earlier, the grain size within the ASB at the shear displacement of $1.8 \mathrm{~mm}$ for the CG austenitic structure is about
$400 \mathrm{~nm}$. These results show that the original stored energy in the matrix has strong influence on the final average grain size within the ASB by deformation-induced grain refinement and dynamic re-crystallization (DRX) under high temperature. The HLS has more stored energy before dynamic shear deformation than the CG austenitic structure, thus the final average grain size within the ASB is smaller in HLS than that in the CG austenitic structure. Moreover, a fraction of $20 \%$ martensite phase (compared to the less than 5\% for the case of the CG austenitic structure) still exists in the ASB although the inverse transformation takes places. These two observations should be the reasons that an obvious peak is observed at $1.8 \mathrm{~mm}$ shear displacement for the HLS.

\section{Concluding remarks}

A series of uniaxial tensile experiments and Hopkinson-bar experiments with hat-shaped specimens have been conducted in the present paper to investigate the quasi-static and dynamic shear responses of 301 SS with GS and HLS. The interesting findings could be summarized as follows:

1. Under quasi-static tensile testing, the $301 \mathrm{SS}$ with GS and HLS show a good combination of strength and ductility due to the strain partitioning, the strain gradient and the back stress hardening for heterogeneous structures.

2. With controlled shear displacement in the hat-shaped specimens, the evolution of ASB of 301 SS with CG austenitic structure has been 
(a)

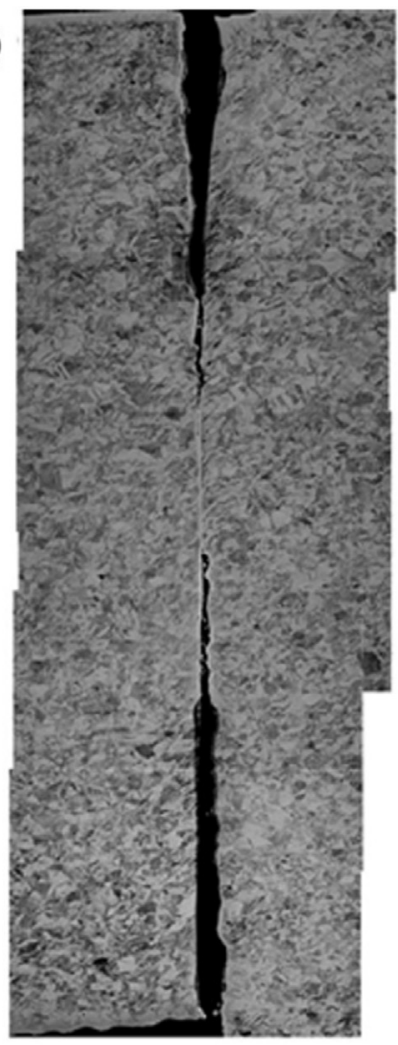

$1.0 \mathrm{~mm}$ (b)

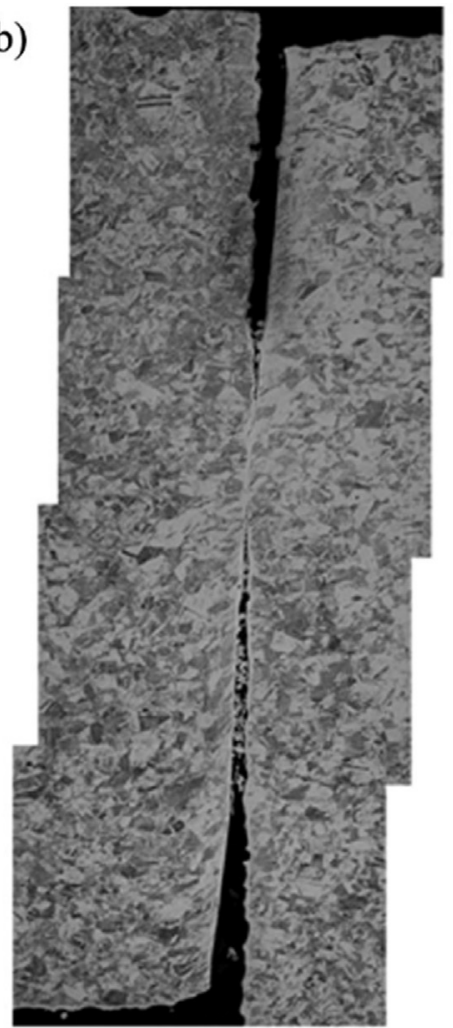

$1.0 \mathrm{~mm}$
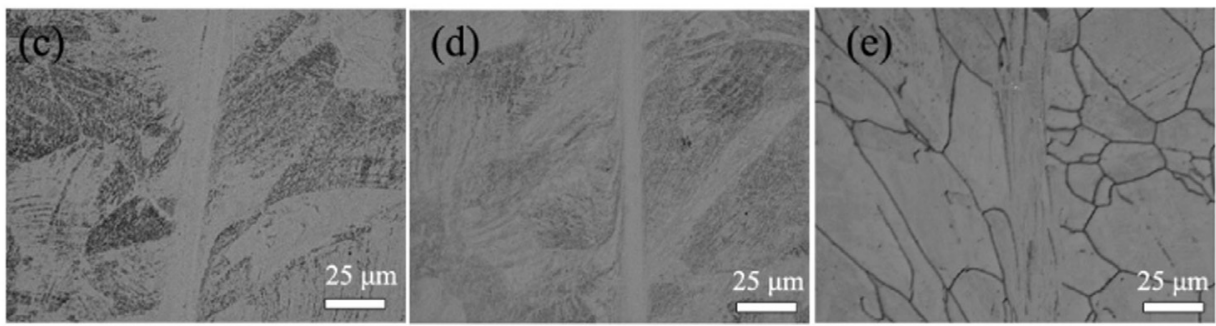

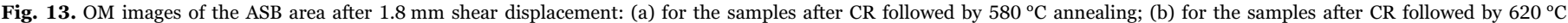
annealing. (c) (d) The corresponding close-up views of the ASB for (a) and (b). (e) The close-up view of the ASB for the CG samples after 1.8 mm shear displacement.

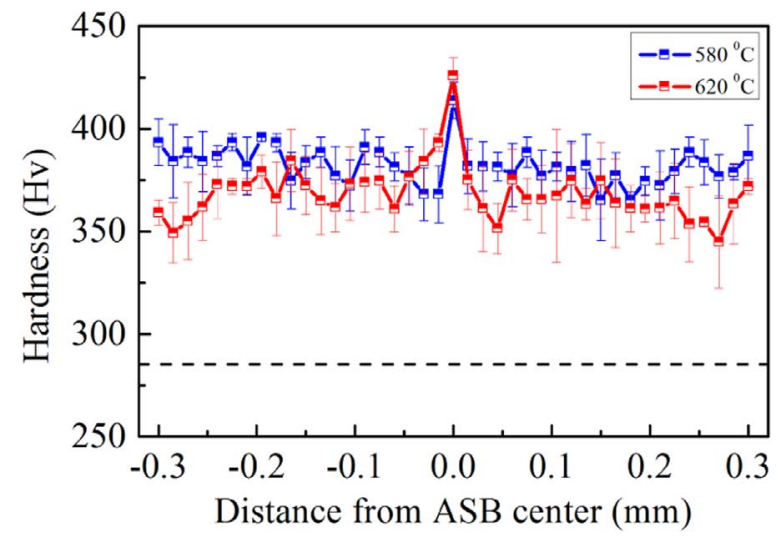

Fig. 14. Vickers micro-hardness distributions traversing the ASB after $1.8 \mathrm{~mm}$ shear displacement for the samples after CR followed by $580^{\circ} \mathrm{C}$ and $620^{\circ} \mathrm{C}$ annealing. The initial hardness for the un-deformed CG austenitic samples is also given by a dashed line.

investigated. Before the formation of ASB, the dynamic shear response shows a strong linear hardening stage followed by a plateau stage, which are due to the martensite transformation and the continuous deformation through strain partitioning between different phases, respectively. The band width was found to increase with increasing shear displacement, and the grain size was observed to significantly refined in the ASB. Once the ASB is nucleated, the reverse phase transformation occurs and the austenite phase increases again in the ASB with increasing shear displacement, resulting in a hardness valley in the ASB.

3. The GS and HLS show excellent dynamic shear properties. The dynamic shear yield strength was found to be more than 2 or 3 times of that of CG austenitic structure while the dynamic shear toughness was observed to be more than half of that of CG austenitic structure. These excellent dynamic shear properties in the GS and HLS could be due to the back stress hardening for either macroscopically or microscopically heterogeneous structures. The HLS seems to have better impact shear properties than the GS, and the reasons could be as follows: The microstructure heterogeneity exists macroscopically between different layers along the depth in the GS, and the ASB could be formed first in the hardest layer at the surface and then propagates along the depth into the center, while the heterogeneity only exists microscopically in the HLS, thus the soft domain could delay the formation of the ASB in the adjacent hard domain. The 


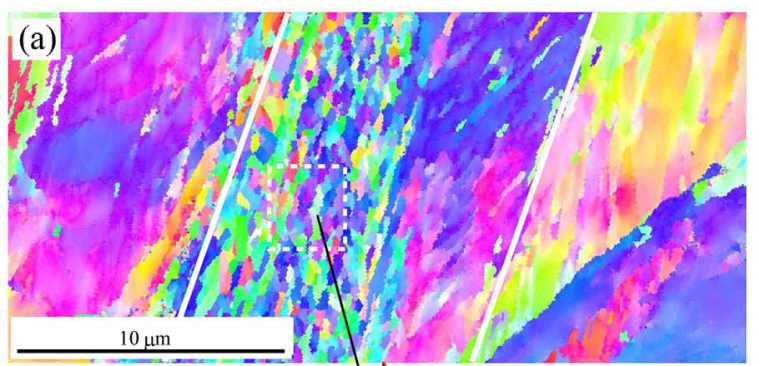

(b)
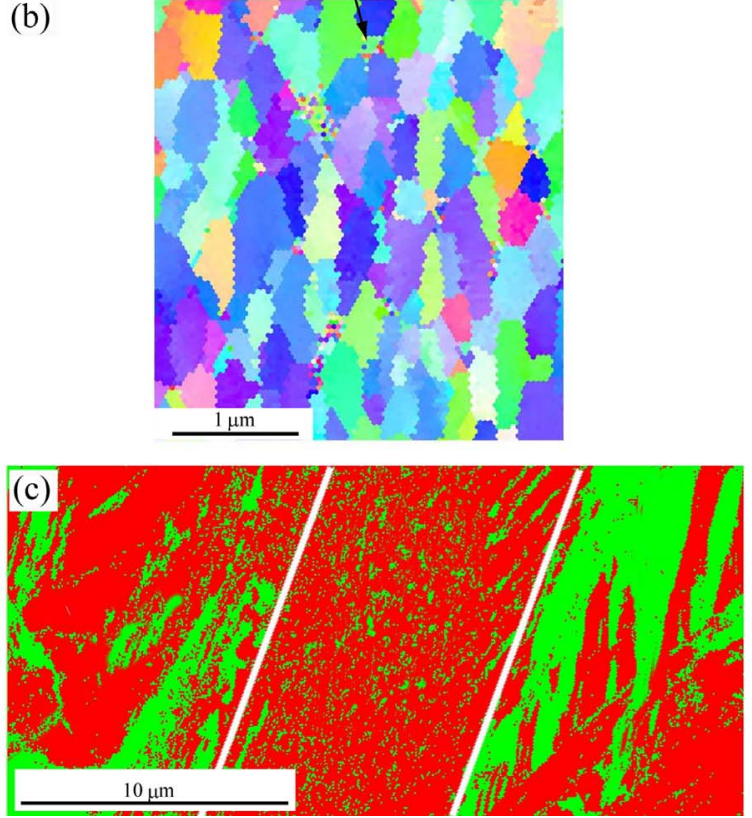

Fig. 15. (a) (c) IPF and phase images of the ASB area after $1.8 \mathrm{~mm}$ shear displacement for the samples after CR followed by $620^{\circ} \mathrm{C}$ annealing. (b) The corresponding close-up view for the rectangular area in (a).

findings in the present study should provide insights for optimizing dynamic properties under impact conditions.

\section{Acknowledgements}

The authors would like to thank the financial support by National Natural Science Foundation of China (Grant Nos. 11472286, 11572328 and 11672313), the Strategic Priority Research Program of the Chinese Academy of Sciences (Grant No. XDB22040503), and National Key Basic Research Program of China (Grant Nos. 2012CB932203 and 2012CB937500). The authors would like to thank Dr. Husheng Zhang for helping to conduct the dynamic shear experiments.

\section{References}

[1] R.Lula, Stainless Steel, American Society for Metals, 1986.

[2] J. Beddoes, J.G. Parr, Introduction to Stainless Steels, 3rd edition, ASM International, Materials Park, OH, USA, 1999.

[3] K.H. Lo, Shek Ch, Lai JKL, Recent developments in stainless steels, Mater. Sci. Eng. R 65 (2009) 39-104.

[4] F.D. Fischer, G. Reisner, E. Werner, K. Tanaka, G. Cailletaud, T. Antretter, A new view on transformation induced plasticity (TRIP), Int J. Plast. 16 (2000) 723-748.

[5] F.P. Yuan, X.L. Wu, Size effect and boundary type on the strengthening of nanoscale domains in pure nickel, Mater Sci. Eng. A 658 (2015) 243-251.

[6] X.L. Wu, M.X. Yang, F.P. Yuan, G.L. Wu, Y.J. Wei, X.X. Huang, Y.T. Zhu, Heterogeneous lamella structure Unites ultrafine-grain strength with coarsegrain ductility, Proc. Natl. Acad. Sci. USA 112 (2015) 14501-14505.

[7] Y.M. Wang, M.W. Chen, F.H. Zhou, E. Ma, High tensile ductility in a nanostructured metal, Nature 419 (2002) 912-915.

[8] X.X. Huang, N. Hansen, N. Tsuji, Hardening by annealing and softening by deformation in nanostructured metals, Science 312 (2006) 249-251.

[9] R.Z. Valiev, Nanostructuring of metals by severe plastic deformation for advanced properties, Nat. Mater. 3 (2004) 511-516.
[10] Y.T. Zhu, X.Z. Liao, Nanostructured metals: retaining ductility, Nat. Mater. 3 (2004) 351-352.

[11] M.M. Wang, C.C. Tasan, D. Ponge, A. Kostka, D. Raabe, Smaller is less stable: size effects on twinning vs. transformation of reverted austenite in TRIP maraging steels, Acta Mater. 79 (2014) 268-281.

[12] M.M. Wang, C.C. Tasan, D. Ponge, A.C. Dippel, D. Raabe, Nanolaminate transformation-induced plasticity-twinning-induced plasticity steel with dynamic strain partitioning and enhanced damage resistance, Acta Mater. 85 (2015) 216-228.

[13] M. Calcagnotto, Y. Adachi, D. Ponge, D. Raabe, Deformation and fracture mechanisms in fine- and ultrafine-grained ferrite/martensite dual-phase steels and the effect of aging, Acta Mater. 59 (2011) 658-670.

[14] D. Raabe, D. Ponge, O. Dmitrieva, B. Sander, Nanoprecipitate-hardened $1.5 \mathrm{GPa}$ steels with unexpected high ductility, Scr. Mater. 60 (2009) 1141-1144.

[15] Bhadeshia HKDH, Nanostructured bainite, Proc. R. Soc. A 466 (2010) 3-18.

[16] Y. Ma, J.E. Jin, Y.K. Lee, A repetitive thermomechanical process to produce nanocrystalline in a metastable austenitic steel, Scr. Mater. 52 (2005) 1311-1315.

[17] A. Di Schino, M. Barteri, J.M. Kenny, Effects of grain size on the properties of a low nickel austenitic stainless steel, J. Mater. Sci. 38 (2003) 4725-4733.

[18] S. Rajasekhara, P.J. Ferreira, L.P. Karjalainen, A. Kyröläinen, Hall-Petch behavior in ultra-fine-grained AISI 301LN stainless steel, Met. Mater. Trans. A 38A (2007) $1202-1210$.

[19] C.X. Huang, G. Yang, C. Wang, Z.F. Zhang, S.D. Wu, Mechanical behaviors of ultrafine-grained 301 austenitic stainless steel produced by equal-channel angular pressing, Met. Mater. Trans. A 42A (2011) 2061-2071.

[20] T.H. Fang, W.L. Li, N.R. Tao, K. Lu, Revealing extraordinary intrinsic tensile plasticity in gradient nano-grained copper, Science 331 (2011) 1587-1590.

[21] Y.J. Wei, Y.Q. Li, L.C. Zhu, Y. Liu, X.Q. Lei, G. Wang, Y.X. Wu, Z.L. Mi, J.B. Liu, H.T. Wang, H.J. Gao, Evading the strengthductility trade-off dilemma in steel through gradient hierarchical nanotwins, Nat. Commun. 5 (2014) 3580.

[22] X.L. Wu, P. Jiang, L. Chen, F.P. Yuan, Y.T. Zhu, Extraordinary strain hardening by gradient structure, Proc. Natl. Acad. Sci. USA 111 (2014) 7197-7201.

[23] X.L. Wu, M.X. Yang, F.P. Yuan, L. Chen, Y.T. Zhu, Combining gradient structure and TRIP effect to produce austenite stainless steel with high strength and ductility, Acta Mater. 112 (2016) 337-346.

[24] G. Subhash, G. Ravichandran, B.J. Pletka, Plastic deformation of hafnium under uniaxial compression, Met. Mater. Trans. A 28A (1997) 1479-1487.

[25] S. Nemat-Nasser, W.G. Guo, Thermomechanical response of DH-36 structural steel over a wide range of strain rate and temperatures, Mech. Mater. 35 (2003) 1023-1047.

[26] B. Song, W. Chen, B.R. Antoun, Determination of early flow stress for ductile specimens at high strain rates by using a SHPB, Exp. Mech. 47 (2007) 671-679.

[27] A. Mishra, M. Martin, N.N. Thadhani, B.K. Kad, E.A. Kenik, M.A. Meyers, Highstrain rate response of ultra-fine-grained copper, Acta Mater. 56 (2008) 2770-2783.

[28] S. Prüger, A. Seupel, M. Kuna, A thermomechanically coupled material model for TRIP-steel, Int J. Plast. 55 (2014) 182-197.

[29] T. Suo, Y.L. Li, K. Xie, F. Zhao, K.S. Zhang, Q. Deng, Experimental investigation on strain rate sensitivity of ultra-fine grained copper at elevated temperatures, Mech. Mater. 43 (2011) 111-118.

[30] T. Suo, Y.L. Li, F. Zhao, X.L. Fan, W.G. Guo, Compressive behavior and ratecontrolling mechanisms of ultrafine grained copper over wide temperature and strain rate ranges, Mech. Mater. 61 (2013) 1-10.

[31] F.P. Yuan, X.D. Bian, P. Jiang, M.X. Yang, X.L. Wu, Dynamic shear response and evolution mechanisms of adiabatic shear band in an ultrafine-grained austeniteferrite duplex steel, Mech. Mater. 89 (2015) 47-58.

[32] F.P. Yuan, P. Chen, Y.P. Feng, P. Jiang, X.L. Wu, Strain hardening behaviors and Strain rate sensitivity of gradient-grained Fe under compression over a wide range of Strain rates, Mech. Mater. 95 (2016) 71-82.

[33] Q. Wei, L. Kecskes, T. Jiao, K.T. Hartwig, K.T. Ramesh, E. Ma, Adiabatic shear banding in ultrafine-grained Fe processed by severe plastic deformation, Acta Mater. 52 (2004) 1859-1869.

[34] Q. Wei, T. Jiao, K.T. Ramesh, E. Ma, L.J. Kecskes, L. Magness, R. Dowding, V.U. Kazykhanov, R.Z. Valiev, Mechanical behavior and dynamic failure of highstrength ultrafine grained tungsten under uniaxial compression, Acta Mater. 54 (2006) 77-87.

[35] Q. Wei, H.T. Zhang, B.E. Schuster, K.T. Ramesh, R.Z. Valiev, L.J. Kecskes, R.J. Dowding, L. Magness, K. Cho, Microstructure and mechanical properties of super-strong nanocrystalline tungsten processed by high-pressure torsion, Acta Mater. 54 (2006) 4079-4089.

[36] Q. Wei, Strain rate effects in the ultrafine grain and nanocrystalline regimes e influence on some constitutive responses, J. Mater. Sci. 42 (2007) 1709-1727.

[37] X. Yu, Y.L. Li, Q.M. Wei, Y.Z. Guo, T. Suo, F. Zhao, Microstructure and mechanical behavior of ECAP processed AZ31B over a wide range of loading rates under compression and tension, Mech. Mater. 86 (2015) 55-70.

[38] D. Jia, K.T. Ramesh, E. Ma, Failure mode and dynamic of nanophase iron under compression, Scr. Mater. 42 (1999) 73-78.

[39] A. Jérusalem, W. Dickson, M.J. Pérez-Martín, M. Dao, J. Lu, F. Gálvez, Grain size gradient length scale in ballistic properties optimization of functionally graded nanocrystalline steel plates, Scr. Mater. 69 (2013) 773-776.

[40] K. Lu, J. Lu, Nanostructured surface layer on metallic materials induced by surface mechanical attrition treatment, Mater. Sci. Eng. A 375 (2004) 38-45.

[41] Y.J. Chen, Y.J. Li, J.C. Walmsley, S. Dumoulin, S.S. Gireesh, S. Armada, Quantitative analysis of grain refinement in titanium during equal channel angular pressing, Scr. Mater. 64 (2011) 904-907.

[42] J.L. Sun, P.W. Trimby, F.K. Yan, X.Z. Liao, N.R. Tao, J.T. Wang, Shear banding in commercial pure titanium deformed by dynamic compression, Acta Mater. 79 
(2014) 47-58

[43] L.W. Meyer, S. Manwaring, Critical adiabatic shear strength of low alloyed steel under compressive loading, in: L.E. Murr (Ed.)Metallurgical Applications of Shock Wave and High-Strain-Rate Phenomena, Marcel Dekker, New York, 1986, pp. $657-674$.

[44] M.A. Meyers, G. Subhash, B.K. Kad, L. Prasad, Evolution of microstructure and shear-band formation in a-hep titanium, Mech. Mater. 17 (1994) 175-193.

[45] C.A. Bronkhorst, E.K. Cerreta, Q. Xue, P.J. Maudlin, T.A. Mason, G.T. Gray III, An experimental and numerical study of the localization behavior of tantalum and stainless steel, Int J. Plast. 22 (2006) 1304-1335.

[46] Q. Xue, G.T. Gray III, B.L. Henrie, S.A. Maloy, S.R. Chen, Influence of shock prestraining on the formation of shear localization in 304 stainless steel, Met. Mater. Trans. A 36A (2005) 1471-1486.

[47] Y. Yang, F. Jiang, B.M. Zhou, X.M. Li, H.G. Zheng, Q.M. Zhang, Influence of shock prestraining on the formation of shear localization in 304 stainless steel, Mater. Sci. Eng. A 528 (2011) 2787-2794.

[48] F.P. Yuan, P. Jiang, X.L. Wu, Annealing effect on the evolution of adiabatic shear band under dynamic shear loading in ultra-fine-grained iron, Int J. Impact Eng. 50 (2012) 1-8.

[49] B. Song, W. Chen, V. Luk, Impact compressive response of dry sand, Mech. Mater. 41 (2009) 777-785.

[50] M.X. Yang, F.P. Yuan, Q.G. Xie, Y.D. Wang, E. Ma, X.L. Wu, Strain hardening in Fe$16 \mathrm{Mn}-10 \mathrm{Al}-0 .{ }^{86} \mathrm{C}-{ }^{5} \mathrm{Ni}$ high specific strength steel, Acta Mater. 109 (2016) $213-222$.

[51] Y. Bai, B. Dodd, Adiabatic Shear Localization, Pergamon Press, New York, 1992.

[52] T.W. Wright, The Physics and Mathematics of Adiabatic Shear Bands, Cambridge University Press, Cambridge, 2002, pp. 176-177. 